\title{
Facilitation and impairment of event memory produced by photograph review
}

\author{
WILMA KOUTSTAAL and DANIEL L. SCHACTER \\ Harvard University, Cambridge, Massachusetts \\ MARCIA K. JOHNSON \\ Princeton University, Princeton, New Jersey \\ and \\ LISSA GALLUCCIO \\ Harvard University, Cambridge, Massachusetts
}

\begin{abstract}
Selectively reviewing some items from a larger set of previously learned items increases memory for the items that are reviewed but may also be accompanied by a cost: Memory for the nonreviewed items may be impaired relative to cases where no review occurs at all. This cost to nonreviewed items has primarily been shown in contexts of verbal list learning and in situations where the reviewed and nonreviewed items are categorically or semantically related. Using a more naturalistic impetus to selective review-photographs relating to previously experienced events-we assessed whether the memory of older and younger adults for unrelated complex activities that they themselves had performed was also impaired due to nonreview. Both younger and older adults showed impaired memory for nonreviewed activities when tested with free recall (Experiment 1), but not when tested with recognition or cued recall (Experiment 2). If mitigating retrieval cues are unavailable, selective review may impair memory for nonreviewed everyday events.
\end{abstract}

Reflecting upon our earlier experiences-recalling what we saw, thought, and did - is a common and familiar human activity (Edwards \& Middleton, 1988; Kotkin, 1978; Tessler \& Nelson, 1994). At various times and in different ways - sometimes alone, sometimes in conversation with others, sometimes with no external prompts to recollection but at other times in the presence of specific reminders - we recall or review events from the past. Yet, however frequent or extensive such review may be, it is necessarily selective. Some events are reviewed and others are not. What are the consequences of such selectivity, particularly for those events that we do not review?

On the one hand, there is clear evidence-from both laboratory paradigms and naturalistic observations - that review may enhance memory for the events that are reviewed. Facilitation of memory for reviewed compared with nonreviewed events has been observed for autobiographical events (Linton, 1975, 1978), and for relatively simple experimentally presented items such as single words or paired associates (e.g., Allen, Mahler, \& Estes, 1969; Cull, Shaughnessy, \& Zechmeister, 1996; Landauer \& Bjork, 1978). Enhanced memory for reviewed events

This research was supported by National Institute on Aging Grant AG08441 and NIA Grant AG09253. We thank Carolyn Brenner for help with scoring in Experiment 1 and G. A. Radvansky, Bobbie Spellman, and Mari Zaragoza for insightful reviews. Correspondence should be addressed to W. Koutstaal, Department of Psychology, Harvard University, William James Hall, 33 Kirkland Street, Cambridge, MA 02138 (e-mail: wk@wjh.harvard.edu). has also been observed for comparatively complex, experimentally presented materials or situations (Hudson, 1990; Suengas \& Johnson, 1988). For example, older adults (age 60-75 years) and younger adults (18-30 years) who watched a videotape of everyday events and interactions and subsequently reviewed some of those events, either through looking at photographs (Koutstaal, Schacter, Johnson, Angell, \& Gross, 1998; Schacter, Koutstaal, Johnson, Gross, \& Angell, 1997) or reading brief verbal descriptions of the events (Koutstaal et al., 1998), showed enhanced memory for those events, both relative to the events they had not reviewed (Schacter et al., 1997) and relative to participants who received no review at all (Koutstaal et al., 1998).

On the other hand, there is also evidence-particularly from list learning studies, but also from other laboratory paradigms - that the consequences of selective review for our subsequent memory may not be entirely benign: Review not only may increase memory for the reviewed events but may also (at least under some circumstances) decrease memory for related but nonreviewed events. For example, Anderson, Bjork, and Bjork (1994) have shown that repeated "practice" at retrieving a subset of previously learned items belonging to a given semantic category (e.g., fruits) may impede memory for the other (nonpracticed) items in the same category, relative to the level of recall observed when no items in a category are practiced at all. There is also at least some evidence that selective review may lead to impaired memory of nonre- 
viewed events of a more complex "episodic" form. In an eyewitness-memory paradigm, Shaw, Bjork, and Handal (1995) first showed participants color slides depicting a crime scene (a student's room in which a theft had occurred) and then repeatedly questioned them about some of the objects from a larger set of similar objects shown in the scene (e.g., college sweatshirts), but asked no questions about another set (the control condition, e.g., college schoolbooks). Participants recalled significantly fewer of the nonreviewed objects if they were from the category about which they had been questioned (e.g., college sweatshirts, about which no questions were asked) than if they were nonreviewed items in the control condition, regarding which no questioning at all had occurred.

Importantly, however, impairment of memory for events that have not been reviewed is not a necessary or inevitable outcome. For example, given the associative nature of memory, it might be expected that reviewing or repeatedly retrieving some of those events should benefit memory for those same events, but it might alsodue to semantic and other associative connections between the reviewed or practiced items and the nonpracticed items - serve to prompt or associatively cue memory for nonreviewed events, to some degree facilitating recall for the nonpracticed items relative to instances where no review occurs at all. Indeed, research using the paradigm known as "part-set cuing" (Nickerson, 1984), where part of a larger set of previously learned items is provided as "cues" for the remaining (nonprovided) items, has pointed to facilitation under some conditions. Facilitation has been observed where the cues provide access to additional studied categories that might not otherwise have been recalled (e.g., Slamecka, 1972; Tulving \& Pearlstone, 1966). However, with the provision of an increasing number of exemplars within the category, impaired recall of the remaining (noncued) items in the category may occur (Roediger, 1973; Rundus, 1973; cf. Roediger \& Neely, 1982).

A common feature of both the Anderson et al. (1994) and Shaw et al. (1995) studies is that the to-be-remembered information belonged to comparatively salient preexisting semantic categories, with decreased memory for the nonreviewed or nonpracticed items in a given category occurring as a consequence of repeated retrieval of other items in the same category (cf. Mueller \& Watkins, 1977). Does selectively reviewing some events from a larger set of events that do not share a clear preexisting semantic relation with one another, but that share other features, such as the spatiotemporal context in which they occurred, also lead to impaired retrieval of the nonreviewed events? From the perspective of the forms of review that we may engage in on an everyday basis, this is an important-but largely unaddressed-question.

Recently, we attempted to assess the extent to which memory for categorically unrelated episodic events might be impaired through selective event review where review was induced, not through verbal questioning, but by providing individuals with an opportunity to review photo- graphs of some events and not others (Koutstaal et al., 1998). Participants first watched a series of complex everyday events on a videotape and then either reviewed one half of those events through looking at photographs of the events (the photograph review group) or received no review (the control group). We then compared participants' ability-at a still later time - to freely recall all of the events they had watched.

Consistent with previous findings involving other forms of event review, there was a clear facilitatory effect of photo review, such that reviewed events were recalled more often, and in greater detail, than nonreviewed events. But in contrast to the findings of Anderson et al. (1994) and Shaw et al. (1995), there was only suggestive evidence for impaired recall of the nonreviewed events, with free recall of nonreviewed events significantly impaired relative to the no-review control condition on only one of several recall measures that were considered (Experiment 1); a further experiment (Experiment 2) provided no evidence of impairment.

The absence of any consistent or substantial impairment in memory for nonreviewed events in these experiments would appear to bode well for our everyday practice of selectively reviewing some events (producing clear gains in the subsequent memorability of those events) but not others (presumably resulting in only relatively minor and/or subtle impairments in the recall of nonreviewed events). Further, these results suggest that the detrimental effects of review for nonreviewed events that have been reported in laboratory studies may be confined to situations where there are preexisting categorical or semantic relations among the reviewed and nonreviewed items. Although no two events or stimuli are likely to be entirely unrelated, these results appear to suggest that--barring more extensive semantic or categorical connections between the target events or stimulireviewing some events from a given spatiotemporal context while excluding others from that review might have only minimal detrimental consequences for the events that were not reviewed.

However, several aspects of these initial experiments may have worked against the observation of an impairment of memory for the nonreviewed events. Taken together, these considerations suggest the need for a further examination of the extent to which categorically unrelated events might be impaired as a consequence of nonreview. First, many participants reviewed photographs only once (older and younger participants in the single-review condition of Experiment 1; all review groups in Experiment 2), and there was some evidence (at least for younger adults) that memory for the nonreviewed events was more impaired with more frequent review. Second, in the multiple-review condition, the repeated review opportunities all occurred within a single, continuous review session (participants reviewed all of the activities once, and then a second and third time with no interpolated time between reviews). It is possible that more temporally distributed reviews would exert a stronger 
effect on memory. For example, "spaced" rather than "massed" review might increase the relative memorability of the reviewed events (Cull et al., 1996; Landauer \& Bjork, 1978), thereby increasing the degree to which they competed with (and therefore rendered less accessible) nonreviewed events. Third, and perhaps most importantly, in these earlier experiments, the reviewed and nonreviewed events were drawn from two different videotaped scenarios, involving different people and different contexts (one took place in an office, the other in a park), with one half of the events in each context reviewed and one half not reviewed. Detrimental effects of prior retrieval on nonretrieved items have been postulated to arise in situations where several events or items are associated to a common retrieval cue: Items associated with a shared retrieval cue are thought to compete, with prior retrieval of an item enhancing the likelihood of later recalling that same item (Anderson \& Bjork, 1994; Anderson et al., 1994), but also decreasing the retrieval strength of the nonrecalled items (Anderson et al., 1994; R. A. Bjork, 1989; also see Brown, 1968; Roediger \& Neely, 1982; Rohrer, 1996; Rundus, 1973). The inclusion of events from two different spatiotemporal contexts may have operated to reduce the amount of competition between events because one half of the reviewed events mapped to one context, whereas the other half of the reviewed events mapped to the other context, and strengthening some of the events in one context (e.g., those that occurred in the office scenario) would not necessarily yield decreases in the strength of nonreviewed events in the other context (e.g., events that occurred in the park scenario). This suggests that greater evidence of reviewinduced memory impairment might be obtained if all of the to-be-remembered events took place in a single spatiotemporal context, and if the photograph review manipulation occurred entirely for items from that one spatiotemporal context.

One aim of the present experiments was to determine whether selectively reviewing some events from a larger set of events would lead to robust impairment of memory for nonreviewed events under conditions where (1) all of the events took place in one general spatiotemporal context, and any detrimental consequences of the exclusion from review would likely be shared by all of the nonreviewed events; and (2) review occurred multipie times, in a temporally distributed manner. To this end, in the present study, a single contextual setting was employed for all of the target events, and each of the reviewed events was reviewed on three separate occasions, separated by 10 -min intervals. In addition, compared with the previous experiment, the total number of events probed was increased: Rather than 24 events, as in the earlier experiments ( 12 of which occurred in one scene, and 12 in the other, with a consequent reviewed-to-nonreviewed mapping of 6:6 for each context), the number of events in the present experiment was 36 , with all of these occurring in the same setting (a reviewed-to-nonreviewed mapping of 18:18).
A second aim of the present experiments was to determine whether selective review would lead to impairment of memory for nonreviewed complex episodic events in a situation where participants themselves took an active part in the events that they later reviewed (or failed to review). Actively involving participants in the activities may provide a closer analogue to situations where review occurs in everyday life as well as providing a further test of the degree to which previous laboratory findings of impaired memory for nonreviewed items might extend to more complex episodic events. Involving participants themselves in the activities might also increase the number and nature of the general contextual features that the events share with one another and-through their cooccurrence in a single experimental context-the degree to which the events might compete with one another at retrieval (and so lead to impaired memory of the nonreviewed items).

A third aim of these experiments was to examine the generality of our findings concerning the possible detrimental effects of postevent review on memory by exploring how review-and nonreview - affects the memory of younger adults (college undergraduates) versus older adults (healthy individuals between 60 and 75 years of age). Older adults have been found to show deficits in the ability to effectively inhibit or suppress no-longer-relevant or to-be-ignored information in a variety of paradigms (for review, see Hasher \& Zacks, 1988; Zacks \& Hasher, 1994). However, age-related deficits in inhibition have emerged primarily in tasks that require the active suppression or exclusion of information from awareness where the distractor information has already - because of its prior relevance or presentation-entered awareness (see, e.g., Hartman, 1995; Hartman \& Hasher, 1991; Hasher, Quig, \& May, 1997; Zacks, Radvansky, \& Hasher, 1996; see also Greenhut-Wertz \& Manning, 1995). For example, older adults may experience greater difficulty suppressing an anticipated but subsequently disqualified ending of a garden-path sentence than younger adults (Hartman, 1995; Hartman \& Hasher, 1991; Hasher et al., 1997) or prove less able to "successfully forget" items that are first presented but then designated as to-be-forgotten (Zacks et al., 1996).

In these examples, information that was recently relevant is maintained in a relatively accessible state, even though subsequent information or events have rendered the information irrelevant or even incorrect. That is, in these cases and many other instances where age-related deficits in inhibition have been observed, the to-besuppressed information might be heuristically classified as both "strong and wrong" (for discussion, see Radvansky \& Curiel, 1998). In contrast, our photograph review paradigm does not appear to require such active attempts at exclusion or suppression of the nonreviewed events from conscious awareness. Although the review procedure does require selective activation (or reactivation) of events during retrieval, this selectivity might be construed more as precluding nonreviewed events from entering 
awareness than as excluding them. Retrieval cues for the nonreviewed events are simply omitted from the photograph review procedure: They are never presented, rather than presented but then designated as to-be-ignored. Thus, if memory for the nonreviewed events is depressed, this likely arises more indirectly (and possibly automatically or unconsciously) as a consequence of retrieving and elaborating on the reviewed events, rather than as a consequence of conscious or deliberate attempts at suppressing or excluding the nonreviewed events from awareness. To the extent that this task analysis is correct, it is possible that the magnitude of impairment, if any, in our paradigm should not differ as a function of age.

\section{EXPERIMENT 1}

The primary goals of this experiment were, first, to determine whether selective event review would lead to impaired memory for nonreviewed events in the "selfperformed activities" photograph review paradigm just described, and, second, to compare the effects of selective review on memory for nonreviewed events in older and younger adults.

The general approach was simple: On their initial visit to the laboratory, participants engaged in 36 different activities. Each activity involved a brief instruction and one or more objects (e.g., "trace the boomerang," for which participants were provided a pencil, a manila sheet of paper, and a yellow plastic boomerang, the outline of which they traced onto the paper). Participants were not explicitly asked to remember the activities but were asked to evaluate them regarding their difficulty, enjoyability, and similarity to activities they performed in their daily lives. Two days later, they returned to the laboratory and were shown photographs of actors performing one half of the activities they had performed; participants were instructed to attempt to use the photographs to remember the activities they themselves had performed, including the nature and perceptual characteristics of the objects that were involved, the actions that they engaged in, and so on. Finally, after two additional reviews of the photographs and a brief delay, participants were asked to freely recall all of the activities they had performed (those that they had reviewed, as well as those they had not reviewed). Recall in this review condition was then compared with recall in a control condition where no photograph review occurred, with these comparisons made both for younger and older adults.

\section{Method}

Participants. Participants were 24 older ( $M$ age $=68.0$ years, $S D=3.3$, range $=61-73)$ and 24 younger $(M$ age $=19.3, S D=$ 1.9 , range $=16-25$ ) individuals, initially recruited through newspaper advertisements and flyers (older adults) or sign-up sheets posted at Harvard University during the regular and summer school academic terms (young adults). Older participants were individually interviewed so as to exclude those with any of the following conditions: a history of alcoholism or substance abuse; cerebrovascular accident; recent myocardial infarction; present or previous treatment for psychiatric illness; current treatment with psychoactive medication; metabolic or drug toxicity; primary degenerative brain disorders (e.g., Alzheimer's disease, Parkinson's disease, or Huntington's disease); or brain damage sustained earlier from a known cause (e.g., hypoxia). Elderly participants had on average approximately 2 more years of formal education $(M=15.5, S D=$ 2.5 , range $=12-21)$ than younger participants $(M=13.3, S D=$ 1.4 , range $=11-16)\left[F(1,46)=13.95, M S_{\mathrm{e}}=4.20, p=.0005\right]$. All participants were native speakers of English, had normal or corrected-to-normal vision, and were paid for their involvement in the experiment.

Stimuli. A set of 36 different activities was created, with each activity involving one or more distinctive objects. For example, one task required participants to trace the outline of a boomerang with a pencil onto a sheet of manila paper; others involved pouring a small quantity of kidney beans into a glass container, hammering a nail into a block of wood, and locating and pointing to Australia on an inflated plastic globe. These activities were subdivided into two sets of 18 activities each (Set A and Set B). Activities were assigned to the two sets so as to approximately equate the sets for the general domains or types of activities they included (e.g., activities involving objects associated with children), the number of objects involved, and whether the activity involved specific "conceptual" or "pictorial" information that could be remembered (e.g., that the song to be found and played on an audiocassette tape was "The Duke of Earl," or that a child's drawing included a picture of a dinosaur). All participants performed the 36 activities in a single, fixed order, with Set $A$ activities (odd-numbered actions) regularly alternating with Set $B$ activities (even-numbered actions). Later, participants in the photograph review conditions reviewed one half of the activities they had performed, reviewing either activities from Set A or Set B (see below).

Photographs. Each of the activities was photographed twice: once with a middle-aged male actor and once with a middle-aged female actor performing the activity. The photographs were taken in a setting identical to that in which experimental participants later performed the activities, using an autofocus hand-held 35-mm camera (Pentax Zoom 90-WR). All of the photographs were taken at a uniform distance from the actors, so that the table surface, on which the objects for most of the activities were placed, was clearly visible, and the actor's head, shoulders, and upper body appeared against a neutral-colored wall. The actors were instructed to look at the objects while they performed the activities and to maintain a relatively neutral facial expression for all of the photographs.

The photographs were $4-\times 6$-in. colored matte finish prints. We began by compiling two photograph subsets for each of the Set A and Set $B$ activities. In one subset (subset $x$ ), the female actor modeled half of the activities and the male modeled the other half (but with the photographs showing the female and male actor pseudorandomly intermixed); in the second subset (subset $y$ ), these were reversed (Set Ax, Set Ay, Set Bx, Set By). Next, within these subsets, the photographs were randomly ordered relative to the sequence in which the activities were actually performed by the experimental participants. A single random order was used for Ax and Ay (which depicted the exact same set of activities but where the gender of the actors was mirror-reversed, such that whereas the male actor performed an action in Set Ax, a female did so in Set Ay, and where the female actor performed an action in Set Ax, the male did so in Set Ay); another similarly constructed random order was used for $\mathrm{Bx}$ and $\mathrm{By}$. The photographs were then inserted into four small photograph albums and the pages were clearly numbered.

These original subsets were used for the first occasion on which participants viewed the photographs. In addition, the photographs within each subset were shown to participants a total of three times, each time in a different random ordering, and separated by 10 -min intervals. For these second and third photograph review sessions, we constructed additional photograph albums using duplicates 
of the photos, creating two further random orderings of the photographs for each set. Thus, in all, a total of 12 different photograph albums were constructed (e.g., Ax-1, Ax-2, Ax-3, Ay-1, Ay-2, Ay-3, etc.). A given participant saw only the photographs from one subset (e.g., the Ax subset), so that any one activity for a given participant was always modeled by the same actor, but the photographed activities were reviewed in a different order on each of the three review occasions. The counterbalancing of photograph conditions across all participants, and within each age group, ensured that each activity was shown equally often with the male and the female as actors.

Procedure. All participants were tested individually, in two sessions, separated by 2 days. At the beginning of the first session, participants were informed that we were interested in assessing their responses to different actions that they would be asked to perform. They were told that the experimenter would first state the action that they were to perform and, immediately thereafter, would place the object or objects needed for the activity on the table (e.g., "I might tell you to 'take a tissue from the box,' in which case I would give you a box of tissues"). Participants were told to perform the relevant action, after which the experimenter would remove the object(s) before proceeding to the next action. After each action, participants were asked to assess the action on each of three different dimensions: how difficult the action was to perform, how enjoyable it was, and how similar the action was to something they might do or see in their everyday life. Participants were provided with a numbered response sheet on which to indicate their ratings, with each of the ratings made on a 5-point scale.

In general, each action required approximately $15-20 \mathrm{sec}$ to complete. The brief experimenter-provided verbal instructions were standardized for all participants (e.g., "Trace the boomerang"). To prevent participants from prospectively or retrospectively viewing the objects, either during performance of the activities or during the later recall phase, a large screen was used to hide all of the objects from view whenever they were not needed for a given activity.

After completing all 36 activities, participants left the laboratory, to return 2 days later. Upon their return, if participants were in the photograph review condition, they were given the following instructions:

You now will be shown photographs of two people (a man and a woman) performing many of the same activities that you performed earlier. I would like you to look carefully at each photograph. At the same time, please try to remember what it was like when you performed the activity-what you did, what the experimenter said, what each of the objects looked like, how the objects felt when you handled them, and so on. In short, use the photograph to try to remember as clearly and completely as you can what you did and what you experienced when you performed the activity yourself.

After you view each photograph, please indicate the degree to which the photo was able to help you to remember the activity. Use a 5-point scale, where "1" indicates that the photo was not at all helpful and " 5 " indicates that the photo was extremely helpful in prompting your memory for the activity.

Participants were then given the first photograph album appropriate for their condition (i.e., Ax-1, Ay-1, Bx-1, or By-1). Each photograph was shown for $20 \mathrm{sec}$, and participants were instructed via an accompanying audiotape when to turn to the next page and when to make their ratings. This procedure of viewing the photographs and rating how helpful they were in prompting memories of the activities was repeated three times, with 10 min intervening between each photograph viewing and the photographs shown in a different random order each time. After the first and second photograph review sessions, participants were given an unstructured break outside the testing room. Participants were not told beforehand how many review sessions would occur. After the third and final review session, participants remained in the testing room and performed an unrelated experiment for $20 \mathrm{~min}$ before being given the free recall test (see below).

Participants in the control condition also returned to the testing room three times at 10-min intervals, but each time they were asked to copy line drawings of three-dimensional abstract figures (from Schacter, Cooper, \& Delaney, 1990) for $6 \mathrm{~min}$, or approximately the duration of a single photograph viewing of the 18 photographs. After the third and final line drawing session, participants in this condition also remained in the testing room and performed an unrelated experiment for $20 \mathrm{~min}$ before receiving the free recall test.

Twenty minutes after the third and final photograph review session (or the third line-drawing session for those in the control condition), participants were given a 30-min free recall test for all of the activities that they had performed. They were asked to try to recall all of the activities they had performed earlier, providing as many details about each activity as possible, and "including the actions that they performed and the names and characteristics of the objects that were involved." To increase the likelihood that participants would attempt to remember all of the activities, they were asked to try to recall the activities in the same order as they had been performed. Participants were provided with lined recall sheets with numbered spaces (1-36) and were instructed to leave spaces on the recall sheet blank if they thought that there were intervening activities that they could not recall. After completion of the free recall test, participants were debriefed.

\section{Results}

Free recall scoring criteria. The free recall protocols were first scored for the number of activities that participants recalled, independently of the amount or nature of the details that were recalled. Credit for recalling an activity was given if participants made a clear and unambiguous (although possibly quite general) reference to either the activity or the objects it involved. The recall protocols were also scored for the specific nature of the memory details or "qualitative characteristics" (e.g., Hashtroudi, Johnson, \& Chrosniak, 1990; M. K. Johnson, Foley, Suengas, \& Raye, 1988) that they contained, including references to particular objects (e.g., boomerang, pencil), actions (e.g., tracing), and pictorial or conceptual information (e.g., "dinosaur," "Australia"). References to perceptual details, including colors (e.g., yellow), texture or material (e.g., plastic), and size or number (e.g., large) were also scored, and then combined into an overall perceptual details measure. ${ }^{\prime}$ Also scored were subjective commentary regarding the activities (e.g., evaluative statements about the appearance of objects), and metamemory comments (e.g., participants' expressions of uncertainty if they were remembering correctly); these were combined into an overall subjective/meta-memory score. Finally, errors (clear mistakes regarding the activities that participants had performed or the objects involved) and sequence errors (errors in the order in which participants recalled the activities relative to the order in which they had been performed) were also scored.

For four of these measures (general event recall, objects, actions, and pictorial or conceptual information), a specific list of possible responses was compiled and participants were given credit only for these responses; thus results for these measures are expressed as proportions. 
The maximum possible scores for Set $\mathrm{A}$ activities for these four measures, respectively, were $18,31,27$, and 23; for Set B activities, the corresponding values were $18,35,27$, and 26 . For three measures (perceptual details, subjective/meta-memory commentary, and errors), no predefined set of possible responses was specified; for these measures, results are expressed as simple "counts." Finally, sequence errors-defined as any occasion when participants "back-tracked" in the recall of activities, recalling an activity that occurred at an earlier point in time after they recalled an activity that occurred at a later point-were expressed in two ways: as a simple frequency count (i.e., the number of sequence errors) and also as a conditionalized value (conditional sequence errors) that took into account the number of opportunities to make such errors. Specifically, because sequence errors might be more frequent for some conditions simply because more events were recalled in those conditions, errors in the order of event recall were also assessed after conditionalizing on the number of events that were recalled: conditional sequence errors $=$ number of sequence errors / (number of recalled activities -1 ), with the subtraction of 1 in the denominator because sequence errors were possible only in instances where more than one event was recalled.

Two scorers, blind to participants' experimental condition, independently scored each of the free recall protocols. For all eight measures (events, objects, actions, pictorial/conceptual information, perceptual details, subjective/meta-memory commentary, errors, and sequence errors), the correlations between the scores of the two raters (computed on Set A and Set B separately and then averaged) ranged between .81 and .99 ; the average interrater correlation was .95 . All analyses were performed on the average of the two raters' scores. ${ }^{2}$

Both facilitation and impairment were assessed on a between-subjects basis. Recall of the reviewed events in the photograph review groups was compared with the level of recall in the control condition to obtain a measure of facilitation; recall of the nonreviewed items in the photograph review groups was compared with the level of recall in the control condition to obtain a measure of impairment. More specifically, each of these comparisons was made against $1 / 2$ (average level of recall in the control condition), since this placed the means for the control condition, which involved a total of 36 events, and the means for the reviewed and nonreviewed events, each of which involved 18 events, on the same scale. Comparisons examining facilitation are presented first, followed by assessments of impairment. An alpha level of .05 was used throughout.

Facilitation comparisons. Table 1 presents the average recall scores obtained on each of the recall measures. The means are shown separately as a function of age and photograph review condition (reviewed $[\mathrm{R}+]$, nonreviewed $[\mathrm{R}-]$ and control), with the proportion measures shown in the upper portion of the table and count measures shown in the lower portion.

We began by considering the effects of photograph review on general recall of the activities (event recall), independently of the number of details recalled. A $2 \times 2$ analysis of variance (ANOVA) treating age (old or young) and photograph review (did or did not see photos) as between-subjects factors was first performed on the average number of events recalled in the control condition (expressed as a proportion out of 18 possible events) versus the average number of events recalled in the photograph review condition $(\mathrm{R}+)$. This analysis revealed a main effect of age $\left[F(1,44)=6.73, M S_{\mathrm{e}}=.02, p=.01\right]$, a main effect of photograph review $[F(1,44)=49.69$, $\left.M S_{\mathrm{e}}=.02, p<.0001\right]$, and an interaction of age with photograph review $\left[F(1,44)=3.90, M S_{\mathrm{e}}=.02, p=.05\right]$. Overall, younger adults recalled more activities (72\%) than did older adults $(61 \%)$, and many more activities were recalled if they had been reviewed via photographs $(81 \%)$ than in the absence of any review (52\%). However, these effects were also modified by an interaction with age, reflecting the fact that older adults benefited considerably more from review (an increment of $37 \%$ relative to the control condition) than did younger adults (an increment of $21 \%$ ). This interaction suggests that, at the level of gaining access to events (regardless of the level of detail

Table 1

Free Recall Results, Experiment 1

\begin{tabular}{|c|c|c|c|c|c|c|c|c|c|c|c|c|c|c|}
\hline \multirow[b]{2}{*}{ Scoring Criterion } & \multicolumn{3}{|c|}{ Old } & \multicolumn{3}{|c|}{ Young } & \multicolumn{4}{|c|}{ Facilitation } & \multicolumn{4}{|c|}{ Impairment } \\
\hline & $\mathrm{R}+$ & $\mathrm{R}-$ & Control & $\mathrm{R}+$ & $\mathrm{R}-$ & Control & Old & Young & $\mathrm{A}$ ? & $\mathrm{A} \times \mathrm{C}$ ? & Old & Young & $\mathrm{A}$ ? & $\mathrm{A} \times \mathrm{C} ?$ \\
\hline \multicolumn{15}{|l|}{ Proportion measures } \\
\hline No. events & .80 & .23 & .43 & .82 & .44 & .62 & $.37^{*}$ & $.20^{*}$ & $\mathrm{Y}$ & $\mathrm{Y}$ & $-.20^{*}$ & $-.18 *$ & $\mathrm{Y}$ & $\mathrm{N}$ \\
\hline Objects & .70 & .19 & .34 & .78 & .39 & .54 & $.36^{*}$ & $.24^{*}$ & $\mathrm{Y}$ & $\mathrm{N}$ & $-.15^{*}$ & $-.15^{*}$ & $\mathrm{Y}$ & $\mathbf{N}$ \\
\hline Actions & .62 & .19 & .32 & .74 & .40 & .53 & $.30^{*}$ & $.21^{*}$ & $\mathrm{Y}$ & $\mathrm{N}$ & $-.13^{*}$ & $-.13^{m}$ & $\mathrm{Y}$ & $\mathrm{N}$ \\
\hline Pictorial/conceptual & .31 & .05 & .17 & .57 & .20 & .28 & $.14^{*}$ & $.29^{*}$ & $\mathrm{Y}$ & $\mathrm{N}$ & $-.12^{*}$ & $-.08^{m m}$ & $\mathrm{Y}$ & $\mathrm{N}$ \\
\hline \multicolumn{15}{|l|}{ Count measures } \\
\hline Perceptual details & 17.46 & 4.96 & 10.15 & 39.96 & 16.75 & 20.33 & $7.31^{\mathrm{m}}$ & $19.63^{*}$ & $\mathrm{Y}$ & $m$ & $-5.19^{m}$ & $-3.58^{\text {n.s. }}$ & $\mathrm{Y}$ & $\mathbf{N}$ \\
\hline Subjective/meta-memory & 1.46 & 0.58 & 1.31 & 7.75 & 4.13 & 2.35 & - & - & - & - & - & - & - & - \\
\hline Errors & 2.88 & 0.88 & 2.02 & 2.96 & 2.13 & 2.17 & - & - & - & - & - & - & - & - \\
\hline Sequence errors & 7.17 & 1.79 & 3.48 & 6.42 & 3.54 & 4.96 & - & - & - & - & - & - & - & - \\
\hline
\end{tabular}

$\mathrm{R}+$, reviewed activities; $\mathrm{R}-$, nonreviewed activities; Facilitation, $\mathrm{R}+$ minus control; Impairment, $\mathrm{R}-$ minus control; $\mathrm{A}$ ?, main effect of age; $\mathrm{A} \times$ $\mathrm{C}$ ?, age $\times$ condition interaction. $\quad{ }^{*} p<.05$ for facilitation or impairment within the relevant age group; $m$ and $m m$, marginally significant $(p<$ $.10, p<.15$, respectively); n.s., nonsignificant $(p>.15)$. 
recalled), older adults gained more from photograph review than did younger adults. However, similar interactions were not observed on any of the further recall measures, involving more specific considerations of what types of information were remembered and, indeed, for one of the measures (perceptual details, see below), a trend toward an interaction in the reverse direction was observed. It is possible that the interaction is due to a ceiling effect: Both older and younger adults recalled approximately $80 \%$ of the reviewed events, and there was very little difference in the level of event recall for older $(80 \%)$ and younger $(82 \%)$ adults, whereas for all other objective measures (objects, actions, pictorial/conceptual information, and perceptual details), younger adults' recall for the reviewed events considerably exceeded that of older adults.

Next we examined possible facilitatory effects of photograph review on the more detailed qualitative measures. For each of the qualitative measures, we performed a separate $2 \times 2$ ANOVA treating age (old or young) and photograph review (did or did not see photographs) as betweensubjects factors. These analyses showed main effects of age on each of the objective measures, with younger adults more often correctly referring to objects $[F(1,44)=10.99$, $\left.M S_{\mathrm{e}}=.02, p=.002\right]$, actions $\left[F(1,44)=20.03, M S_{\mathrm{e}}=\right.$ $.02, p<.0001]$, pictorial/conceptual information $[F(1,44)$ $\left.=13.26, M S_{\mathrm{e}}=.03, p=.0007\right]$, and perceptual details $\left[F(1,44)=20.56, M S_{\mathrm{e}}=155.89, p<.0001\right]$ than older adults. These analyses also revealed main effects of photograph review on each of these measures, with more correct references to objects $\left[F(1,44)=52.12, M S_{\mathrm{e}}=.02\right.$, $p<.0001]$, actions $\left[F(1,44)=47.90, M S_{\mathrm{e}}=.02, p<\right.$ $.0001]$, pictorial/conceptual information $[F(1,44)=18.02$, $\left.M S_{\mathrm{e}}=.03, p=.0001\right]$, and perceptual details $[F(1,44)=$ $\left.13.97, M S_{\mathrm{e}}=155.89, p=.0005\right]$ if activities had been reviewed through photographs than if they had not been reviewed. Although age did not significantly interact with photograph review on any of these measures, there was a trend, on the perceptual details measure, for younger adults to gain more from review than older adults [i.e., a trend toward an interaction in the opposite direction to that observed for the number of events measure $[F(1,44)=$ $\left.2.92, M S_{\mathrm{e}}=155.89, p=.09\right]$. Younger adults also provided more subjective/meta-memory commentary overall than did older adults $\left[F(1,44)=5.68, M S_{\mathrm{e}}=28.39\right.$, $p=.02]$, with this difference tending to be somewhat more pronounced for the photograph review groups than the controls [age $\times$ condition interaction, $F(1,44)=2.91$, $\left.M S_{\mathrm{e}}=28.39, p=.09\right]$.

There were no significant effects, or interaction, for errors $\left[F_{\mathbf{s}}<1.98\right]$. Sequence errors were equally frequent for older $(M=5.3)$ and younger $(M=5.7)$ adults $[F<$ 1], but were more common for reviewed events in the photograph review groups $(M=6.8)$ than in the control group $\left[M=4.2 ; F(1,44)=38.73, M S_{\mathrm{e}}=2.05, p<\right.$ $.0001]$, and the increase in errors as a function of review was especially pronounced for older adults $[F(1,44)=$ $7.27, M S_{\mathrm{e}}=2.05, p=.01$, for the age $\times$ condition inter- action]. However, after conditionalizing on the number of opportunities to make sequence errors, there were no effects of age or review $(F \mathbf{S}<1)$, and no interaction $(F<1.3)$.

Impairment comparisons. The possibility that recall of the nonreviewed events was impaired as a consequence of reviewing other events was assessed by comparing participants' recall of the nonreviewed $(\mathrm{R}-)$ activities in the photograph review condition against the average level of recall in the control condition (expressed as an average out of 18 events, to place it on the same scale as the $\mathrm{R}$ - condition). We first considered effects on the general likelihood of recalling the activities (event recall), independently of the number or nature of additional details recollected. A $2 \times 2$ ANOVA treating age and photograph review (did or did not see photographs) as betweensubjects factors revealed a main effect of age, indicating greater overall recall of the activities by younger than older adults $\left[F(1,44)=19.78, M S_{\mathrm{e}}=.02, p<.0001\right]$. More importantly, this analysis also showed substantial impairment associated with photograph review, so that significantly more activities were recalled in the control condition $(52 \%)$ than in the nonreview $(\mathrm{R}-)$ condition $[34 \%$; $\left.F(1,44)=16.69, M S_{\mathrm{e}}=.02, p=.0002\right]$. Equally important, there was no interaction of review with age $(F<1)$, indicating that both older and younger adults' recall of the nonreviewed events was depressed to a similar degree ( $-20 \%$ for older adults, $-18 \%$ for younger adults).

The possibility that more detailed recollection of the nonreviewed events was also impaired was likewise evaluated. In addition to main effects of age on each of these objective measures $[F \mathrm{~s}(1,44)>14.83]$, there was significant impairment of recall concerning details of the nonreviewed events, pointing to decreased recall as a consequence of photograph review, on three of the four additional objective measures of recall. Significant impairment was observed for the recall of objects $[F(1,44)=$ $\left.11.47, M S_{\mathrm{e}}=.02, p=.002\right]$, actions $[F(1,44)=11.43$, $\left.M S_{\mathrm{e}}=.02, p=.002\right]$, and pictorial/conceptual information $\left[F(1,44)=9.08, M S_{\mathrm{e}}=.01, p=.004\right]$; a similar, but not significant, pattern was observed for the perceptual details measure $\left[F(1,44)=2.62, M S_{\mathrm{e}}=88.04, p=\right.$ .11]. In no instance did these main effects interact with age $(F \mathrm{~s}<1)$.

The last eight columns of Table 1 summarize the extent of facilitation and impairment observed on each of the five objective measures we used. The magnitude of facilitation ( $\mathrm{R}+$ minus control) and impairment $(\mathrm{R}-$ minus control) is shown separately for older and younger adults; also shown are the outcomes of analyses conducted on the older and younger groups considered separately, with asterisks indicating whether facilitation and impairment were significant in each age group alone. These analyses showed that, with only one exception, the facilitatory effects of photograph review that were observed in the combined age groups were also observed in the two age groups taken separately (the exception involved somewhat less strong facilitation of memory for perceptual details in older adults, but the numerical difference was in the same 
direction as that for the combined group and for the other measures). All of the impairment effects that were observed in the combined group were apparent when older adults were considered separately, with older adults' recall of nonreviewed items significantly impaired on the number of events measure and the objects, actions, and pictorial/conceptual information measure; however, for younger adults, impairment on two measures was only marginally significant in the separate age group comparison (actions and pictorial/conceptual information) and, on a further measure, failed to reach significance (perceptual details). Nonetheless, in all cases the numerical differences were in the same direction as for the groups combined, with fewer details recalled for nonreviewed activities-given that other activities were reviewed - than in the control group.

An analysis of errors for the nonreviewed events showed that there was a tendency for younger adults to make more errors than older adults $\left[F(1,44)=3.46, M S_{\mathrm{e}}=\right.$ $1.69, p=.07]$ and also for the control group to make more errors than participants in the experimental condition $\left[F(1,44)=2.50, M S_{\mathrm{e}}=1.69, p=.12\right]$. In terms of the absolute number of sequence errors, mistakes in the order of recall of the nonreviewed events were more common among younger $(M=4.3)$ than older $(M=2.6)$ adults $\left[F(1,44)=11.70, M S_{\mathrm{e}}=2.67, p=.001\right]$ and for individuals in the control group $(M=4.2)$ than for nonreviewed events $\left[M=2.7 ; F(1,44)=10.81, M S_{\mathrm{e}}=2.67\right.$, $p=.002]$. However, there were no differences in the likelihood of sequence errors as a function of age, or review condition, after opportunities for errors were taken into account $(F \mathrm{~s}<1)$.

\section{Discussion}

This experiment has clearly extended the conditions under which detrimental effects of selective review on the recollection of nonreviewed events may be observed: Nonreview may impair the recall of events that-apart from their co-occurrence in a particular episodic contextshare no marked semantic or categorical relations with one another, where review occurs via a relatively "naturalistic" and common prompt for retrieval (that of photographs), and where the "items" that are to be recalled are activities that individuals themselves have performed. Moreover, these detrimental effects were observed in both older and younger adults.

Although, compared with the level of recall observed in the absence of any review, recall of events that were reviewed was clearly facilitated, this benefit was accompanied by a cost: Recall of the nonreviewed events was depressed below what it would have been had no review occurred at all. Significant impairment was observed both at the general level of overall event recall (whether the activity was recalled at all, independently of how much was recalled concerning it) and also on several more specific qualitative measures. Detailed probes of what, more specifically, individuals failed to remember as a consequence of "nonreview" revealed that, combining across the two age groups, selective review led to significantly impaired recall of several forms of information regarding the nonreviewed activities, including comparatively central information (details concerning the objects and actions involved), as well as relatively more abstract or conceptual aspects (pictorial/conceptual information).

Comparisons of the effects of selective review as a function of age showed that both facilitation and impairment of event memory were shown by older and younger adults. Focusing particularly on the impairment comparisons, each of the four recall measures that showed significant impairment in the combined age groups also showed significant impairment in the older age group alone. Compared with the older control group, older adults in the photograph review group recalled fewer of the nonreviewed activities overall; they also recalled fewer details concerning the objects and actions involved, and less often recalled pictorial/conceptual information. These observations contrast with findings from other experimental paradigms that have pointed to age-related impairments in inhibition in tasks that require that initially presented or generated information be actively suppressed or ignored, and where older adults often show less effective suppression than younger adults (e.g., Hartman \& Hasher, 1991; Zacks et al., 1996). However, our observation of largely parallel amounts of impairment in older and younger adults is consistent with the suggestion, made in the introduction, that depressed recall of nonreviewed events in the present paradigm may not strongly depend on conscious or direct exclusion of those events from awareness or attention (cf. Hartman, 1995; Radvansky \& Curiel, 1998). Rather, impaired recall of the nonreviewed events may arise as an indirect consequence of reviewing other events - a result of the competition between the reviewed and nonreviewed events, but where this competition may occur largely outside of awareness, comprising an unintended (and presumably unwelcome) by-product of successful retrieval of the reviewed events.

In both the present experiment, which showed strong impairment of nonreviewed events, and in our earlier experiment (Koutstaal et al., 1998, Experiment 1), which provided only suggestive evidence for impairment, the detrimental effects of selective review were observed during free recall. Explorations of memory impairment that result from other forms of "memory-strengthening" manipulations suggest that observations of impairment may be very dependent on the nature of the retrieval cues present at test, in such a way that alterations in the accessibility of events arising from postevent review and retrieval practice may be most likely to be detected under the minimal cuing conditions of free recall. For example, in a paradigm of directed or "instructed" forgetting that is believed to minimize the likelihood that there are differences in the initial encoding of the to-be-remembered and to-be-forgotten information (the "list" or "block" cuing paradigm), impairment of memory as a consequence of the instruction to forget is typically observed 
under free recall testing, but not during recognition testing (e.g., Basden, Basden, \& Gargano, 1993; for review, see R. A. Bjork, 1989; H. M. Johnson, 1994). Similarly, explorations of memory for nonstrengthened items in paradigms that compare items that are repeatedly presented during study (strengthened items) with those that are not repeated have pointed to impairment in free recall, with little or no decrement observed in recognition (Ratcliff, Clark, \& Shiffrin, 1990; Tulving \& Hastie, 1972). On the basis of parallels between these paradigms and our postevent procedure, it might be expected that providing participants with retrieval cues regarding the nonreviewed events should increase the accessibility of those events and diminish or even eliminate the impairment that we found under the limited cuing conditions of free recall.

However, in contrast with these findings, Anderson et al. (1994) found that repeatedly retrieving some items from a semantic category (e.g., banana), but not others, led to impaired memory for nonreviewed items even when recall for the nonpracticed items was probed using quite specific recall cues for the items (e.g., FRUIT-O or FRUIT-OR___ Such impairment was observed only for items that were highly typical of the category (such as orange); it was not observed for less typical exemplars (such as kiwi).

This observation of impairment for nonreviewed strong exemplars-despite the presence of fairly specific recall cues-is important because it provides evidence against other possible sources of impaired memory for the nonreviewed items that do not necessarily derive from suppression of the nonreviewed items, but rather from blocking or "interference" from the reviewed items. The next experiment examined whether impaired memory for nonreviewed complex episodic events would be observed under conditions that provided stronger retrieval cues at the time of testing and where contributions due to "output interference" from the reviewed items might be reduced.

\section{EXPERIMENT 2}

We used the same experimental paradigm as that in Experiment 1, where individuals first performed activities in the laboratory and then reviewed half of those activities through the photograph review procedure (photograph review condition) or performed an unrelated control task instead (control condition). However, thereafter, rather than free recall, participants were given a combined cued recall and recognition test.

For this test, participants were provided a written list of 72 different objects and were informed that some of these objects had been involved in the activities that they had performed on their previous visit, whereas other objects were not involved in the activities. For each of the objects listed, participants were asked to first indicate whether they thought the object was "old"- that is, involved in one of the activities they had performed-or "new"- that is, never involved in the activities they had performed. In addition, individuals in the photograph re- view conditions were explicitly told that they should base their decisions on whether or not the object was involved in one of the activities they had performed; they were instructed, "Please be aware that not all of the activities that you performed were shown in the photographs, so you should think carefully about each object and decide whether or not it was involved in one of the activities you did." Further, beside each item, additional space was provided. Participants were asked, for any item that they called "old," to write everything that they could remember about the activity they had performed, providing as many details about each activity as possible, including information about the actions they had performed and the names and characteristics of the objects involved. They were asked to recall both characteristics of the object that was listed as a retrieval cue and characteristics of any additional objects that had been involved in the same activity, and were told that it was very important that they respond to the items in the order in which they appeared on the sheet. Participants provided their old/ new judgments, and any recollected details, for each item before proceeding to the next item. The order of items on the recognition/cued recall test was pseudorandom, with studied or "old" items interspersed with nonstudied or "new" items.

\section{Method}

Participants. Sixteen older $(M$ age $=67.9$ years, $S D=3.4$, range $=62-74)$ and 16 younger $(M$ age $=20.3$ years, $S D=2.0$, range $=18-26)$ individuals, recruited in the same manner as in Experiment 1 , participated. Participants were pseudorandomly assigned to experimental conditions in such a way that 8 individuals from each age group were shown photographs ( 2 in each of the four conditions, $\mathrm{Ax}, \mathrm{Ay}, \mathrm{Bx}, \mathrm{By}$ ), and 8 were not shown photographs (the control condition).

Procedure. The overall procedure was identical to that of Experiment 1 except, rather than receiving a free recall test, participants were given the combined recognition/cued recall test.

\section{Results}

Recognition. Overall performance on the verbal recognition test showed a high level of accuracy: Combining across the two age groups and the photograph review manipulation, participants correctly recognized $83 \%$ of the objects from the activities they had performed and false alarmed to only $4 \%$ of the distractor items. Facilitatory effects due to photograph review were examined first. A $2 \times 2$ ANOVA, performed on correct recognition responses (hits) and treating age (old or young) and photograph review (did or did not see photos) as betweensubjects factors, revealed significant effects of age and review: Older adults $(M=.81)$ correctly recognized fewer items than did younger adults $[M=.94 ; F(1,28)=$ $\left.9.84, M S_{\mathrm{e}}=.01, p=.004\right]$, and participants in the photograph review condition $(M=.95)$ recognized more of the reviewed events than did participants in the control condition $\left[M=.80 ; F(1,28)=14.66, M S_{\mathrm{e}}=.01, p=\right.$ $.0007]$. Relative to the control condition, facilitation of reviewed events was observed for both older adults $(M \mathrm{~s}=$ 
.91 vs. .71$)$ and younger adults $(M \mathrm{~s}=.99$ vs. $.88 ; F<1.2$ for the age $\times$ condition interaction).

Next, to assess the presence of impairment, a similar analysis was performed on the correct recognition scores for the nonreviewed events in the photograph review condition versus the control group. This analysis revealed a significant effect of age $\left[F(1,28)=17.56, M S_{\mathrm{e}}=.02\right.$, $p=.0003]$, and no other effects $(F \mathrm{~s}<1)$. Older adults recognized fewer items overall $(M=.67)$ than did younger adults $(M=.87)$, but overall recognition of nonreviewed events in the photograph review group $(M=.76)$, although numerically lower than in the control group $(M=.80)$, was not significantly depressed.

Cued recall. The cued recall protocols were scored in the same manner as the free recall protocols of Experiment 1, with two exceptions: First, participants were not given credit for the recall of objects that were themselves provided as recall cues on the recognition/cued recall test, and second, no separate measure of event recall was obtained (event recall in the present experiment was essentially identical to the yes/no recognition measure, described above). Interrater correlations for scoring of the cued recall measures were again high, ranging from .68 to .99 for all six measures, and yielding an average interrater correlation of .88. As in Experiment 1, all analyses were computed on the average of the two raters' scores.

Table 2 presents the means for each of the cued recall measures, with results shown separately as a function of age and photograph review status: reviewed $(\mathrm{R}+)$, nonreviewed $(\mathrm{R}-)$, and control.

Facilitation comparisons. Separate $2 \times 2$ ANOVAs treating age (old/young) and review condition (did or did not see photographs) as between-subjects factors were conducted on each of the cued recall measures. These analyses revealed consistent main effects of age across all four of the objective recall measures. Older adults recalled fewer objects $\left[F(1,28)=25.93, M S_{\mathrm{e}}=.02, p<\right.$ $.0001]$ and actions $\left[F(1,28)=26.22, M S_{\mathrm{e}}=.01, p<\right.$ $.0001]$, and less pictorial/conceptual $[F(1,28)=19.45$, $\left.M S_{\mathrm{e}}=.02, p=.0001\right]$ and perceptual $[F(1,28)=20.07$, $\left.M S_{\mathrm{e}}=242.93, p=.0001\right]$ information than did younger adults. Although younger adults also tended to provide somewhat more subjective commentary and meta-memory remarks than older adults, this difference was not significant $\left[F(1,28)=2.51, M S_{\mathrm{e}}=15.02, p=.12\right]$. The two age groups did not differ in number of errors $[F<1]$.

These analyses also showed main effects of photograph review for each of the four objective indexes of memory. Compared with participants in the control group, participants in the photograph review conditions more often referred to specific objects $\left[F(1,28)=38.56, M S_{\mathrm{e}}=\right.$ $.02, p<.0001]$, actions $\left[F(1,28)=17.18, M S_{\mathrm{e}}=.01\right.$, $p=.0003]$, pictorial/conceptual information $[F(1,28)=$ 17.32, $M S_{\mathrm{e}}=.02, p=.0003$ ], and perceptual details $\left[F(1,28)=19.82, M S_{\mathrm{e}}=242.93, p=.0001\right]$.

These main effects of age and photograph review were, in two instances, modified by interactions of age with review condition. An age $\times$ review condition interaction was observed for references to perceptual details $\left[F(1,28)=6.98, M S_{\mathrm{e}}=242.93, p=.01\right]$, and a trend toward an interaction was also observed for the pictorial/ conceptual information measure $\left[F(1,28)=3.47, M S_{\mathrm{e}}=\right.$ $.02, p=.07]$. These interactions reflected the fact that, in absolute terms, younger adults gained more as a function of photograph review on these measures than did older adults. A trend toward an age $\times$ review condition interaction was also observed for the perceptual details measure in Experiment 1, suggesting that postevent review may prove less beneficial for the recollection of these types of details for older adults than for younger adults. More detailed analyses of the type of perceptual details that were recalled by the two age groups, considering references to "colors," "size or number," and "textures or materials" separately, showed that references to colors, and to texture or materials, were especially depressed among older adults; speculatively, this may reflect impaired "binding" of color and object information, or texture and object information, among older adults (see Chalfonte \& Johnson, 1996; M. K. Johnson \& Chalfonte, 1994).

Impairment comparisons. As in Experiment 1, the possible presence of an impairment of memory for non-

Table 2

Recognition and Cued Recall Results, Experiment 2

\begin{tabular}{|c|c|c|c|c|c|c|c|c|c|c|c|c|c|c|}
\hline \multirow[b]{2}{*}{ Scoring Criterion } & \multicolumn{3}{|c|}{ Old } & \multicolumn{3}{|c|}{ Young } & \multicolumn{4}{|c|}{ Facilitation } & \multicolumn{4}{|c|}{ Impairment } \\
\hline & $\mathrm{R}+$ & $\mathbf{R}-$ & Control & $\mathrm{R}+$ & $\mathrm{R}-$ & Control & Old & Young & A? & $\mathrm{A} \times \mathrm{C} ?$ & Old & Young & A? & $\mathrm{A} \times \mathrm{C}$ ? \\
\hline \multicolumn{15}{|l|}{ Proportion measures } \\
\hline ( No. events) & 91 & .63 & .71 & .99 & .89 & .88 & $.20^{*}$ & $.11^{*}$ & $\mathrm{Y}$ & $\mathrm{N}$ & $-.08^{\text {n.s. }}$ & $+.01 \mathrm{n.s}$ & $Y$ & $\mathrm{~N}$ \\
\hline Objects & .68 & .38 & .38 & .93 & .72 & .63 & $.30^{*}$ & $.30^{*}$ & $\mathrm{Y}$ & $\mathrm{N}$ & $.00^{\text {n.s. }}$ & $+.09^{\text {n.s. }}$ & $\mathrm{Y}$ & $\mathrm{N}$ \\
\hline Actions & .66 & .43 & .48 & .83 & .73 & .70 & $.18^{*}$ & $.13^{*}$ & $\mathrm{Y}$ & $\mathbf{N}$ & $-.05^{\mathrm{n.s.}}$ & +.03 n.s. & $\mathrm{Y}$ & $N$ \\
\hline Pictorial/conceptual & .24 & .10 & .13 & .52 & .31 & .25 & $.11^{m}$ & $.27^{*}$ & $\mathrm{Y}$ & $m$ & $-.03^{\text {n.s. }}$ & $+.06^{\text {n.s. }}$ & $\mathrm{Y}$ & $N$ \\
\hline \multicolumn{15}{|l|}{ Count measures } \\
\hline Perceptual details & 18.75 & 7.38 & 8.78 & 58.00 & 30.00 & 18.91 & $9.97^{\mathrm{mm}}$ & $39.09 *$ & $\mathrm{Y}$ & $\mathrm{Y}$ & $-1.40^{\mathrm{n} . \mathrm{s}}$ & $+11.09^{m}$ & $\mathrm{Y}$ & $m$ \\
\hline Subjective/meta-memory & 3.50 & 1.19 & 1.72 & 5.81 & 6.63 & 3.75 & - & - & - & - & - & - & - & - \\
\hline Errors & 1.38 & 1.00 & 2.09 & 1.88 & 2.19 & 1.97 & - & - & - & - & - & - & - & - \\
\hline
\end{tabular}

$\mathrm{R}+$, reviewed activities; $\mathrm{R}-$, nonreviewed activities; Facilitation, $\mathrm{R}+$ minus control; Impairment, $\mathrm{R}-$ minus control; $\mathrm{A}$ ?, main effect of age; $\mathrm{A}$ $\times \mathrm{C}$ ?, age $\times$ condition interaction. ${ }^{*} p<.05$ for facilitation or impairment within the relevant age group; $m$ and $m m$, marginally significant $(p<$ $10, p<.15$, respectively); n.s., nonsignificant $(p>.15)$. 
reviewed events was assessed by comparing recall performance for the nonreviewed $(\mathrm{R}-$ ) activities in the photograph review condition with the level of recall in the control condition. Separate 2 (age) $\times 2$ (review condition) ANOVAs were conducted on each of the cued recall measures, including recall for the nonreviewed activities as the dependent measure for the photograph review condition, and the average level of recall (divided by 2 , to place it on the same scale as the R-condition) for the control condition. These analyses revealed main effects of age for each of the objective measures, with younger adults' recall exceeding that of older adults for objects, actions, pictorial/conceptual information, and perceptual details $\left(F_{\mathrm{S}}>19.2\right)$; younger adults also provided more subjective/meta-memory commentary than did older adults $\left[F(1,28)=17.86, M S_{\mathrm{e}}=6.25, p=.0002\right]$. However, in marked contrast with the outcomes of Experiment 1 , there was no evidence of impairment on any of the objective measures of recall $(F \mathrm{~S}<1$ for objects, actions, and pictorial/conceptual information; $F<2$ for perceptual details). Consideration of each of the age groups separately showed slight but nonsignificant impairment of recall for nonreviewed events among older adults (impairment of $0 \%-5 \%$ for the three proportion measures; see Table 2), whereas younger adults showed slightly greater recall of the nonreviewed events than in the control condition (facilitation for nonreviewed events of $3 \%$ $9 \%$ for the three proportion measures). This differential pattern as a function of age was particularly apparent for the perceptual details measure, where (1) among younger adults, recall for the nonreviewed events was marginally greater than in the control group $\left[F(1,14)=3.50, M S_{\mathrm{e}}=\right.$ $140.75, p=.08]$, and (2) there was a trend toward an age $\times$ condition interaction $\left[F(1,28)=3.30, M S_{\mathrm{e}}=94.80\right.$, $p=.08]$. There was also a trend for younger, but not older, participants in the photograph review groups to provide more subjective commentary and meta-memory remarks regarding the nonreviewed events than that observed for participants in the control group $\left[F(1,28)=3.72, M S_{\mathrm{e}}=\right.$ $6.25, p=.06$ for the age $\times$ condition interaction].

\section{Discussion}

The primary finding from the present experiment concerns the near-elimination (and, in the case of younger adults, partial reversal) of the impairment in recall for nonreviewed events with the provision of more extensive retrieval cues at the time of testing. Memory of nonreviewed events was significantly impaired relative to that in a no-review control condition when participants' memory was probed with free recall (Experiment 1 , significant overall impairment on the number of events recalled measure, and the objects, actions, and pictorial/conceptual information measures). In contrast, either slight and nonsignificant impairment (older adults) or slight facilitation (younger adults) of memory for nonreviewed events was observed when memory was probed with a combination of recognition and cued recall (Experiment 2).
Note that because impairment reflects a difference score in the recall of two groups (the $\mathrm{R}-$ items of the photograph review group vs. average recall in the control group), an absence of impairment for nonreviewed events might occur either because (1) recall of the $\mathrm{R}-$ items was greater with retrieval cuing than without it, or (2) recall in the control group did not benefit from retrieval cues or failed to benefit as much as recall of the $\mathrm{R}-$ items. To try to determine the contributions of these two factors to the present outcome, one might compare the levels of recall for the $\mathrm{R}-$ and control conditions in this experiment relative to those of Experiment 1. However, for some of the measures, comparisons across the two experiments are not possible because the measures differed in some manner across the experiments (e.g., the "number of events" measure involved free recall in Experiment 1 but recognition in Experiment 2; also, the "objects" measure differed in the two experiments because some of the objects were provided as recall cues in Experiment 2, and participants received credit only for the nonprovided objects). Nonetheless, results for the remaining objective measures-actions, pictorial/conceptual information, and perceptual details-can be compared.

Consideration of the results for the first of these three measures (actions) suggests that-as expected-recall of actions among the control participants increased with the provision of retrieval cues in Experiment 2. Recall of actions for older controls in Experiment 1 was 32\% versus $48 \%$ in Experiment 2 (an increment of $16 \%$ ); younger controls showed a similar pattern, with recall of $53 \%$ in Experiment 1 versus 70\% in Experiment 2 (an increment of $17 \%$ ). However, this increase in the recall performance of the control group was also accompanied by an even greater increase in the recall of actions associated with the nonreviewed $(\mathrm{R}-)$ events: The recall of actions for nonreviewed eventș among older adults was $19 \%$ in Experiment 1 versus $43 \%$ in Experiment 2 (an increase of $24 \%$ ); the corresponding values for younger adults were $40 \%$ versus $70 \%$ (an increase of $30 \%$ ). Finally, although both older and younger adults also showed an increase in recall of actions for the reviewed events as a result of the retrieval cues, the increase was of a smaller magnitude than for either the control group or the nonreviewed items (increments from Experiment 1 to Experiment 2 of 4\% and $9 \%$ for older and younger adults, respectively).

Thus the pattern of differences for the actions measure was that recall for the nonreviewed $(\mathrm{R}-)$ events showed the largest benefit as a result of the more extensive retrieval cues provided at test, followed by the control condition, and then reviewed $(\mathrm{R}+)$ events. For the other two dependent measures (pictorial conceptual information and perceptual details), there were smaller increments, and recall in the control group and for $\mathrm{R}+$ items did not benefit from retrieval cues; however, for these two measures, too, there was some increment in performance for the $\mathrm{R}-\mathrm{items}$ (increments of $5 \%$ and $11 \%$ for pictorial/conceptual information for older and younger adults, 
respectively; increments of 2.42 and 13.25 for perceptual details, respectively).

Together, these comparisons suggest that the absence of impairment in the cued recall of nonreviewed events in the present experiment was due to a combination of two factors: a relative failure to gain from retrieval cuing on the part of the controls (particularly for the pictorial/ conceptual and perceptual details measures) and-more consistently - a "disproportionate" gain achieved in the recall of nonreviewed $(\mathrm{R}-)$ events in the presence of retrieval cues. Possible accounts of these findings are assessed below.

\section{GENERAL DISCUSSION}

Together, these experiments provide evidence for (1) the possible detrimental effects of selective review on memory for complex and unrelated everyday events, as shown by participants' diminished free recall of nonreviewed events relative to the level of recall observed when no review occurred at all (Experiment 1) and (2) the highly cue-dependent nature of this impairment, with the detrimental effects of nonreview that were observed during free recall testing completely eliminated in recognition and cued recall (Experiment 2). These findings will be discussed in turn, followed by a consideration of agerelated differences, and then the general implications of our findings.

\section{Impaired Recall of Nonreviewed Events During Free Recall Testing}

The observation, in Experiment 1, of significant impairment as a consequence of postevent review is comparable to findings from retrieval practice and other "item-strengthening" paradigms, where detrimental consequences of retrieving some events on the likelihood of retrieving other events have also been shown (e.g., Anderson et al., 1994; Shaw et al., 1995; see also Ratcliff et al., 1990; Tulving \& Hastie, 1972). However, the present results extend these observations to instances of comparatively more complex episodic events that did not share clear or consistent preexisting semantic relations with one another, and in which participants themselves actively engaged. We observed significant impairment of memory for activities that participants themselves had performed, including decreased recall of objects, actions, and pictorial/conceptual details. Moreover, because our experimental design, like that of Anderson et al. (1994) but unlike that of Shaw et al. (1995), involved an interpolated delay between the postevent review and ultimate testing, it appears that these detrimental effects of postevent review for nonreviewed events may be comparatively enduring, and do not depend on a short delay between initial practice and attempted retrieval. In this respect, our findings are dissimilar to memory impairment observed in part-set cuing paradigms (Nickerson, 1984) with either semantic materials (e.g., Brown,
1968; Karchmer \& Winograd, 1971) or recently learned list materials (e.g., Mueller \& Watkins, 1977), where impairment of noncued items is observed as a consequence of providing a subset of previously learned items as "cues" for the remaining items, but where these cues are given either directly before, or during, the time of retrieval (see Anderson et al., 1994). In the present paradigm, we observed detrimental effects due to prior selective review on a free recall test that was administered 20 min after the last review occasion, when the cues for the $\mathrm{R}+$ events were no longer present. Moreover, this impairment was observed despite the encouragement to participants to try to recall the activities in the temporal order in which they had occurred-a strategy intended (but apparently unsuccessful) as a means of providing an alternative and nonbiased "retrieval route" to the events (see Fisher \& Geiselman, 1988; Geiselman, Fisher, MacKinnon, \& Holland, 1986; Koutstaal \& Schacter, 1997).

\section{Absence of Impaired Memory of Nonreviewed Events in Cued Recall and Recognition}

The complete absence of memory impairment for the nonreviewed events in Experiment 2, when recall cues were provided, is at least partially consistent with several possibilities. One possibility is that the retrieval cues acted to overcome a form of active suppression or "inhibition" of the nonreviewed activities. Such active inhibition may have been observed in free recall, and not in cued recall, because the recall cues were sufficient to overcome the inhibition. Active inhibition may have emerged during the photograph review phase, where selective recall of the photographically cued events may have entailed competitive inhibition of the noncued events that occurred in the same context, or during free recall itself, where more rapid and possibly repeated recall of the reviewed events may have resulted in decreased activation strength of the nonreviewed events. For example, Anderson and Spellman (1995; see also Anderson \& Bjork, 1994) have argued that the selective retrieval of particular targets from memory may involve actively suppressing the to-be-ignored (not currently selected) nontarget items, either through a process of lateral inhibition or through a process of pattern suppression. This type of process might be termed inhibition in a strict sense, involving an actual reduction in the activation of the representation of an item. However, demonstrating that a decrement in memory comprises "inhibition" in this strict sense is difficult (see Anderson \& Spellman, 1995, for discussion), and (as developed further below) our experiments-although not inconsistent with such an account - also provide no clear evidence in favor of inhibition in this sense.

A second possibility is that repeated retrieval of some of the activities and not others resulted in a form of "retrieval inhibition" that did not involve suppression of the representation itself, but involved decreased accessibility of the item to episodic retrieval. For example, in the 
list- or block-cuing directed forgetting procedure, described earlier, the instruction to forget a set of previously encountered items may result in decreased accessibility of the to-be-forgotten items on some tests but not others, suggesting that the representation itself is not suppressed, though intentional access to it is, in some way, precluded. In this paradigm, evidence for the decreased accessibility of the to-be-forgotten material may be observed in the form of reduced proactive interference from the to-beforgotten items. Thus, when participants are asked to recall only the to-be-remembered items, recall of a to-beremembered list preceded by a to-be-forgotten list may be equivalent to that observed in a control group where only a single (to-be-remembered) list had been presented (R. A. Bjork, 1989). Decreased accessibility has also been shown in diminished free recall of the to-be-forgotten items relative to the to-be-remembered items when the to-be-forgotten items are probed directly, using free recall or cued recall (e.g., Basden et al., 1993). However, this form of "retrieval inhibition" does not seem to involve decreased activation of the representation itself because impaired memory for the to-be-forgotten items that is observed during recall testing is eliminated during recognition testing (e.g., Basden et al., 1993), and may even be eliminated by reexposure to only a subset of the to-be-forgotten items if those items occur during a test involving reference to the study episode (R. A. Bjork, 1989; E. L. Bjork \& R. A. Bjork, 1996). Thus, the present findings are consistent with "retrieval inhibition" of this form, and also with "release from inhibition" in the face of retrieval cues (note the comparatively "disproportionate" gains for the R-items in Experiment 2 as a function of the retrieval cues) ${ }^{3}$

Nonetheless, the cue-dependent nature of the memory impairment observed in Experiment 2 appears to be inconsistent with two previously reported findings of impairment arising as a result of retrieval practice. Perhaps most directly comparable to the present results are the findings of Shaw et al. (1995), who found that repeated questioning led to impaired memory of nonpracticed items on a cued recall test. However, the recall cues in the Shaw et al. study were essentially category cues: The postevent questioning concerned one half of two sets of objects shown in the slides (either college sweatshirts or college schoolbooks), and the recall cues consisted of these category labels (i.e., the recall cues were "college sweatshirts" or "college schoolbooks"). This contrasts with the recall cues of Experiment 2 in the present study, which were highly event or item specific. The recall cues in Experiment 2 were the names of the objects from the activities. These objects constituted highly distinctive and central aspects of the activities, and their inclusion on the cued recall test likely "re-presented" a key component of the initial experience to participants. Thus the comparatively greater benefits that we observed as a function of the cues relative to those observed by Shaw et al. are not especially surprising.
A similar argument cannot be applied to the recall cues used by Anderson et al. (1994) in their semantic retrieval practice paradigm, where impairment of nonpracticed category items was observed not only in free recall (Experiment 1) but also when a combination of category cues and item-specific information was presented (e.g., fruit together with either the stem o___ or the stem OR__ when one of the studied items had been orange). However, impaired recall was found only for items that were strong exemplars of the category (e.g., orange) and not for items that were weak exemplars (e.g., kiwi). To the extent that many of the activities in the current paradigm were likely more analogous to the weak than the strong exemplars-inasmuch as they occurred only once and were only one of a total of 36 events - it is possible that the two findings are reconcilable.

However, an analysis that we conducted in an attempt to examine this possibility also argues against this further proposal. In an exploratory spirit, we attempted to determine if the trends toward impairment of nonreviewed activities that were observed for older adults in Experiment 2 would prove to be greater if only relatively strong items were considered. To operationally define comparatively "strong" items, we examined the recall protocols of older adults in the control group from $E x$ periment 1 , reasoning that, given that these individuals did not receive any review, the likelihood that they would recall any activity under free recall might be used to estimate the "baseline strength" of the item. Those activities that were recalled (on the event recall measure) by at least half of the older participants in the control condition of Experiment 1 were considered relatively "strong" events (across the 12 control participants, 16 of the 36 activities were recalled by at least half of the participants, with 8 of these "often recalled" activities from Set $\mathrm{A}$, and 8 from Set B). We then confined consideration of the recall results for older adults in Experiment 2 to these "strong" events, obtaining a total recall score for the four objective measures (objects, actions, pictorial/ conceptual information, and perceptual details). An analysis of these total scores revealed significant facilitation, with the number of details recalled for the reviewed events (27.75) nearly twice that for the control group [15.50; $\left.F(1,14)=6.62, M S_{\mathrm{e}}=90.61, p=.02\right]$. However, a comparison of the nonreviewed events with events from the control group showed no impairment, with recall of details concerning these "strong" $\mathrm{R}$ - events essentially equivalent $(15.88)$ to that of the control group $(15.50, F<1)$.

The latter outcome suggests that a differing pattern of performance for the "strong" versus "weak" items is unlikely to account for the difference between the findings of Anderson et al. (1994; impaired memory of strongly associated nonpracticed items, despite the presence of fairly specific recall cues) and those of our Experiment 2 (no evidence of memory impairment for nonreviewed events when specific recall cues were provided). Other differences between the experiments, however, may be 
important in accounting for the conflicting findings. Perhaps most importantly, although the recall cues of Anderson et al. were fairly specific, the cues differed in two ways from those used in the present Experiment 2: (1) They were incomplete (participants needed to generate the completion), and (2) they provided both item-specific and categorical information. In contrast, the recall cues in the present experiment required no completion and provided only item-specific information. The more complete provision of item-specific information, and the absence of categorical cuing in the present experiment may have allowed an effective "by-passing" of a retrieval route through the shared contextual cues of the events, thus minimizing any interference from the other events (whether reviewed or not). For instance, given the highly specific recall cue "boomerang," individuals might immediately or directly recall the activity that they performed with the boomerang, or other aspects of their encounter with it (e.g., that the boomerang was yellow and plastic), with minimal interference arising from the other activities they performed. In contrast, the cue FRUIT$\mathrm{OR} \_$, even if it does successfully cue orange, does so by first cuing the category of fruits - and thus may increase competition from other items within the category.

A third possible interpretation of the cue-dependent nature of the impairment that we observed involves output interference. It is possible that the decrement in the free recall of the nonreviewed events arose because of the excessive accessibility of the reviewed items: During attempted recall, the reviewed items may have been recollected more readily than nonreviewed items and may have interfered with or blocked the retrieval of less accessible nonreviewed events. Although such an output interference interpretation cannot be ruled out, if impaired free recall of the nonreviewed items derived exclusively from the blocking effects of recalling the reviewed events, then impairment should also have been observed in our previous experiments (Koutstaal et al., 1998), where free recall of reviewed events was also strongly and consistently facilitated. However, in marked contrast with the present findings, in the earlier experiments there was only slight and inconsistent evidence for impairment, with impairment observed on only one of several measures in one experiment, and no impairment observed in a further experiment. Although there are many differences between these two sets of experiments, it appears possible that factors that have previously been postulated to play a role in other forms of retrieval impairment - such as the number of items that are mapped to a common retrieval cue or that share overlapping contextual features with one another and so may be affected by the strengthening or failure to strengthen similar eventsmay be important.

The "cue-dependent" nature of the memory impairment that we observed is - at least at a broad conceptual level - also consistent with the outcome of a further analysis that we performed, where we considered not just the overall level of recall of the nonreviewed events, but also the number of recollected details after conditionalizing on event recall. If the decreased recall of nonreviewed events that we observed in Experiment 1 derived primarily from a failure to "access" those events during retrieval, so that these events were more likely to be left out of participants' recall than were the reviewed events, then it might be expected that - after taking into account the differing number of events that were recalled-the number of details per recalled event should no longer differ for the nonreviewed events relative to the number for the control group. Summing across the various "objective" measures (objects, actions, pictorial/conceptual information, and perceptual details) to obtain an overall measure of recall, and then dividing by the number of events that were recalled, this was precisely what we found: The average number of details supplied per recalled event in Experiment 1 was nearly identical for the no-review control group (5.02) and the nonreviewed events (4.97). Further, although older adults also showed impairment relative to the young on this conditionalized measure, neither age group showed an effect of review status (older adults $=4.50$ and 4.20 for the no-review controls and nonreviewed events, respectively; younger adults $=5.43$ and 5.84, respectively, $F \mathrm{~s}<1$ for the effect of review status and for the age $\times$ review status interaction). This suggests that the effect of selective review was to reduce the likelihood that an event would be recalled, but-given that it was recalled-memory for nonreviewed events was largely similar to that found among control participants, who received no review at all.

In contrast, a similar conditionalized analysis for the reviewed events indicated that the facilitatory effects that were observed for these events did not entirely disappear when the differing number of events that were recalled was taken into account: For Experiment 1, there was still a trend toward an effect of review status in the conditionalized analysis $\left[F(1,44)=3.28, M S_{\mathrm{e}}=1.62, p=\right.$ .08 ], and for Experiment 2, significant facilitation was seen $\left[F(1,44)=28.81, M S_{\mathrm{e}}=1.12, p<.0001\right]$. On this conditionalized measure, older adults tended to show less pronounced facilitation than did younger adults, with a trend toward an age $\times$ review status interaction emerging in Experiment $1\left[F(1,44)=2.76, M S_{\mathrm{e}}=1.62\right.$, $p=.10]$ and a significant interaction found in Experiment $2\left[F(1,44)=5.48, M S_{\mathrm{e}}=1.12, p=.03\right]$. However, the latter difference was largely carried by the agerelated deficit in facilitation for perceptual details (also found in Experiments 1 and 2), with the differential effects of review for older and younger adults considerably less marked, and nonsignificant, when perceptual details were excluded from the conditionalized measure.

\section{Effects of Age}

A final observation regards the consequences of postevent review for older relative to younger adults. The primary focus of the present experiments concerned the possible presence of impaired memory of the nonre- 
viewed events in older adults. Our results clearly showed that older adults' memory for nonreviewed events was depressed at least to the same degree as that of younger adults - indeed, decrements were more consistently observed across measures for older adults in Experiment 1, and numerical differences were at least in the direction of impairment for older adults in Experiment 2. However, the present experiments also provided further evidence regarding the nature and extent of facilitation achieved through postevent review in older and younger adults. In previous experiments using the photograph review paradigm, where memory for reviewed and nonreviewed events was assessed by free recall (Koutstaal et al., 1998), we found that older and younger adults gained as much from photograph review primarily when using a relative index of facilitation: Although older adults tended to gain less from photograph review than younger adults in absolute terms, if the benefit derived from review was expressed as a proportion of overall recall, then the relative benefit of older and younger adults was equivalent. This result contrasted with findings obtained in two further experiments in which, rather than free recall, memory was assessed with a verbal yes/no recognition test (Schacter et al., 1997). In the latter experiments, older and younger adults also showed equivalent gains from photograph review in absolute terms (rather than only in relative terms). In the present experiments, the absolute benefits from retrieval practice for older adults (and not only relative benefits) approximated the level of benefit for younger adults for most of the recall measures used (the notable exception concerned perceptual details, where a trend toward an age $\times$ review interaction was observed in Experiment 1 and a significant interaction was observed in Experiment 2). Across experiments, these findings point to the reliability of the finding that older adults can achieve substantial benefits from postevent review and suggest that older and younger adults may often achieve comparable benefits. Indeed, in the present experiments, both the potential mnemonic benefits (for the reviewed events) and the potential mnemonic hazards (for the nonreviewed events) of postevent review through photographs affected older and younger adults equally.

\section{Broader Implications}

The practical implications of the present findings are clear: Selective review of some events from our past may not only facilitate our memory for those events, but may impede memory for events that are not reviewed-at least under conditions where external cues are unavailable to overcome the negative effects of nonreview. Indeed, in the second experiment, although we provided prompts to guide the selective review of some activities and not others at the time of photograph review, we provided effectively exhaustive prompts for retrieval at the time of testing; that is, objects from all of the activities that participants had originally performed were included on the recognition/cued recall test. It is unlikely that, in settings outside the laboratory, all of the events experienced in a given spatiotemporal context will receive cuing, and even more unlikely that the prompts that do occur will invariably constitute highly distinctive cues to those events. In everyday life, the prompts to review are likely to constitute a more partial subset of all events, and the cues themselves are likely to comprise to some extent overlapping or shared and thus "ambiguous" reminders of experiences. To the extent that this is true, the selectivity of postevent review may have ongoing detrimental consequences, even when some counteracting retrieval cues are present. Thus our collective and individual identities may be partially shaped not only by enhanced memory for what it is that we have reviewed (see Edwards \& Middleton, 1988; Kotkin, 1978; Tessler \& Nelson, 1994), but also by a "positive absence"-or impairment of memory-for what was not reviewed.

\section{REFERENCES}

Allen, G. A., Mahler, W. A., \& Estes, W. K. (1969). Effects of recall tests on long-term retention of paired associates. Journal of Verbal Learning \& Verbal Behavior, 8, 463-470.

ANDERSON, M. C., \& BJORK, R. A. (1994). Mechanisms of inhibition in long-term memory: A new taxonomy, in D. Dagenbach \& T. H. Carr (Eds.), Inhibitory processes in attention, memory, and language (pp. 265-325). San Diego: Academic Press.

ANDERSON, M. C., BJORK, R. A., \& BJORK, E. L. (1994). Remembering can cause forgetting: Retrieval dynamics in long-term memory. Journal of Experimental Psychology: Learning, Memory, \& Cognition, 20, 1063-1087.

Anderson, M. C., \& Spellman, B. A. (1995). On the status of inhibitory mechanisms in cognition: Memory retrieval as a model case. Psychological Review, 102, 68-100.

Basden, B. H., Basden, D. R., \& Gargano, G. J. (1993). Directed forgetting in implicit and explicit memory tests: A comparison of methods. Journal of Experimental Psychology: Learning, Memory, \& Cognition, 19, 603-616.

BJORK, E. L., \& BJORK, R. A. (1996). Continuing influences of to-beforgotten information. Consciousness \& Cognition, 5, 176-196.

BJoRK, R. A. (1989). Retrieval inhibition as an adaptive mechanism in human memory. In H. L. Roediger III \& F. I. M. Craik (Eds.), Varieties of memory and consciousness: Essays in honour of Endel Tulving (pp. 309-330). Hillsdale, NJ: Erlbaum.

BRoWN, J. (1968). Reciprocal facilitation and impairment of free recall. Psychonomic Science, 10, 41-42.

Chalfonte, B. L., \& Johnson, M. K. (1996). Feature memory and binding in young and older adults. Memory \& Cognition, 24, 403-416.

Cull, W. L., Shaughnessy, J. J., \& Zechmeister, E. B. (1996). Expanding understanding of the expanding-pattern-of-retrieval mnemonic: Toward confidence in applicability. Journal of Experimental Psychology: Applied, 2, 365-378.

EDWARDs, D., \& MidDleton, D. (1988). Conversational remembering and family relationships: How children learn to remember. Journal of Social \& Personal Relationships, 5, 3-25.

FisheR, R. P., \& GEISELMAN, R. E. (1988). Enhancing eyewitness memory with the cognitive interview. In M. M. Gruneberg, P. E. Morris, \& R. N. Sykes (Eds.), Practical aspects of memory: Current research and issues (Vol. 1, pp. 34-39). New York: Wiley.

Geiselman, R. E., Fisher, R. P., MacKinnon, D. P., \& Holland, H. L. (1986). Enhancement of eyewitness memory with the cognitive interview. American Journal of Psychology, 99, 385-401.

Greenhut-WerTZ, J., \& ManNing, S. K. (1995). Suffix effects and 
intrusion errors in young and elderly subjects. Experimental Aging Research, 21, 173-190.

HARTMAN, M. (1995). Aging and interference: Evidence from indirect memory tests. Psychology \& Aging, 10, 659-669.

Hartman, M., \& Hasher, L. (1991). Aging and suppression: Memory for previously relevant information. Psychology \& Aging, 6, 587-594

HASHER, L., QUIG, M. B., \& MAY, C. P. (1997). Inhibitory control over no-longer-relevant information: Adult age differences. Memory \& Cognition, 25, 286-295.

HASHER, L., \& ZACKS, R. T. (1988). Working memory, comprehension, and aging: A review and a new view. Psychology of Learning \& Motivation, 22, 193-225.

Hashtroudi, S., Johnson, M. K., \& Chrosniak, L. D. (1990). Aging and qualitative characteristics of memories for perceived and imagined complex events. Psychology \& Aging, 5, 119-126.

Hudson, J. A. (1990). Constructive processing in children's event memory. Developmental Psychology, 26, 180-187.

JoHnson, H. M. (1994). Processes of successful intentional forgetting. Psychological Bulletin, 116, 274-292.

Johnson, M. K., \& ChaLfonte, B. L. (1994). Binding complex memories: The role of reactivation and the hippocampus. In D. L. Schacter \& E. Tulving (Eds.), Memory systems 1994 (pp. 311-350). Cambridge, MA: MIT Press.

Johnson, M. K., Foley, M. A., Suengas, A. G., \& Raye, C. L. (1988). Phenomenal characteristics of memories for perceived and imagined autobiographical events. Journal of Experimental Psychology: General, 117, 371-376.

KARCHMER, M. A., \& WinOGRAD, E. (1971). Effects of studying a subset of familiar items on recall of the remaining items: The John Brown effect. Psychonomic Science, 25, 224-225.

KotKIN, A. (1978). The family photo album as a form of folklore. Exposure, 16, 4-8.

KoutstaAl, W., \& Schacter, D. L. (1997). Inaccuracy and inaccessibility in memory retrieval: Contributions from cognitive psychology and neuropsychology. In P. S. Appelbaum, L. A. Uyehara, \& M. R. Elin (Eds.), Trauma and memory: Clinical and legal controversies (pp. 93-137). New York: Oxford University Press.

Koutstaal, W., Schacter, D. L., Johnson, M. J., Angell, K. E., \& Gross, M. S. (1998). Post-event review in older adults: Improving memory accessibility of complex everyday events. Psychology \& Aging, 13, 277-296.

LANDAUER, T. K., \& BJoRK, R. A. (1978). Optimum rehearsal patterns and name learning. In M. M. Gruneberg, P. E. Morris, \& R. N. Sykes (Eds.), Practical aspects of memory (pp. 625-632). New York: Academic Press.

LinTon, M. (1975). Memory for real-world events. In D. A. Norman \& D. E. Rumelhart (Eds.), Explorations in cognition (pp. 376-404). San Francisco: Freeman.

Linton, M. (1978). Real world memories after 6 years: An in vivo study of very long-term memory. In M. M. Gruneberg, P. E. Morris, \& R. N. Sykes (Eds.), Practical aspects of memory (pp. 3-24). New York: Academic Press.

MuelleR, C. W., \& Watkins, M. J. (1977). Inhibition from part-set cuing: A cue-overload interpretation. Journal of Verbal Learning \& Verbal Behavior, 16, 699-709.

NiCKERSON, R. S. (1984). Retrieval inhibition from part-set cuing: A persisting enigma in memory research. Memory \& Cognition, 12, 531-552.

RadVANSKy, G. A., \& CURIEL, J. M. (1998). Narrative comprehension and aging: The fate of completed goal information. Psychology \& Aging, 13, 69-79.

RATCLIFF, R., CLARK, S. E., \& SHIFFRIN, R. M. (1990). List-strength effect: I. Data and discussion. Journal of Experimental Psychology: Learning, Memory, \& Cognition, 16, 163-178.

ROEDIGER, H. L., III (1973). Inhibition in recall from cueing with recall targets. Journal of Verbal Learning \& Verbal Behavior, 12, 644-657.
RoEDIGER, H. L., III, \& NEELY, J. H. (1982). Retrieval blocks in episodic and semantic memory. Canadian Journal of Psychology, 36, 213-242.

ROHRER, D. (1996). On the relative and absolute strength of a memory trace. Memory \& Cognition, 24, 188-201.

RuNDUS, D. (1973). Negative effects of using list items as recall cues. Journal of Verbal Learning \& Verbal Behavior, 12, 43-50.

Schacter, D. L., Cooper, L. A., \& Delaney, S. M. (1990). Implicit memory for unfamiliar objects depends on access to structural descriptions. Journal of Experimental Psychology: General, 119, 5-24.

Schacter, D. L., Koutstaal, W., Johnson, M. K., Gross, M. S., \& ANGELL, K. E. (1997). False recollection induced by photographs: A comparison of older and younger adults. Psychology \& Aging, 12, 203-215.

SHAW, J. S., III, BJORK, R. A., \& HANDAL, A. (1995). Retrieval-induced forgetting in an eyewitness-memory paradigm. Psychonomic Bulletin \& Review, 2, 249-253.

SLAmeCKa, N. J. (1972). The question of associative growth in the learning of categorized materials. Journal of Verbal Learning \& Verbal Behavior, 11, 324-332.

SUENGAS, A. G., \& JoHnson, M. K. (1988). Qualitative effects of rehearsal on memories for perceived and imagined complex events. Journal of Experimental Psychology: General, 117, 377-389.

TEsSler, M., \& Nelson, K. (1994). Making memories: The influence of joint encoding on later recall by young children. Consciousness \& Cognition, 3, 307-326.

TUlVING, E., \& Hastie, R. (1972). Inhibition effects of intralist repetition in free recall. Journal of Experimental Psychology, 92, 297-304.

Tulving, E., \& Pearlstone, Z. (1966). Availability versus accessibility of information in memory for words. Journal of Verbal Learning \& Verbal Behavior, 5, 381-391.

ZACKS, R. T., \& HASHER, L. (1994). Directed ignoring: Inhibitory regulation of working memory. In D. Dagenbach \& T. H. Carr (Eds.), Inhibitory processes in attention, memory, and language (pp. 241-264). San Diego: Academic Press.

ZaCKs, R. T., RADVANSKY, G., \& HASHER, L. (1996). Studies of directed forgetting in older adults. Journal of Experimental Psychology: Learning, Memory, \& Cognition, 22, 143-156.

\section{NOTES}

1. Note that, insofar as more detailed event memory is likely to be manifested across several different qualitative dimensions, these various indices of correctly recalled information will tend to be positively correlated with one another. For the two experiments reported here, the average pairwise correlations of the five objective measures of recall (general event recall, and recall of objects, actions, pictorial/conceptual information, and perceptual details) were .66 (Experiment 1 ) and .72 (Experiment 2). In general, the intercorrelations among the measures of event recall, objects, and actions were especially strong, with the picto$\mathrm{rial} / \mathrm{conceptual}$ and perceptual detail measures showing somewhat less strong correlations with these measures.

2. With one exception, all scoring was performed by two of the authors (W.K. and L.G.); the exception concerned sequence errors, which were scored by W.K. and a third rater.

3. If the impairment in memory for the $\mathrm{R}$ - events arose from a form of retrieval inhibition, such as that shown in list-cued directed forgetting, it might be expected that impairment of R - events could also be observed during recognition testing if response latency rather than accuracy were used as the dependent measure. Consistent with this, recognition latencies for the to-be-forgotten items have been shown to be longer than for to-be-remembered items, even though accuracy is not impaired (Zacks et al., 1996).

(Manuscript received June 17, 1997; revision accepted for publication May 28,1998 .) 